\title{
Sustaining Change in Radiology Education: The Need for Universal Curricula
}

\author{
Darel E. Heitkamp, Karen S. Johnson, Robert D. Suh, Harprit S. Bedi, Sandra A. A. Oldham,
} Christopher P. Ho, Angelisa M. Paladin

The pace of change in today's graduate medical education (GME) environment has been swift [1]. For the better part of a decade, organizations such as the Accreditation Council for Graduate Medical Education (ACGME) have contributed to a massive list of new requirements for postgraduate medical training. Many of these requirements call for individual programs to create their own educational content and assessment tools without meaningful guidance or tangible resources from the organizations requiring the changes. For most programs, compliance has been challenging.

\section{EDUCATORS AS POLICY ENFORCERS}

The barrage of new policy has indeed been substantial, as nearly every aspect of radiology residency training was overhauled between 2005 and 2015 [2-7]. To summarize, there has been a complete redesign of residency structure, an overhaul of the ABR board exams, a new mandatory system of trainee evaluation that includes the use of specialty-specific milestones, a new system by which GME training programs are evaluated by the ACGME, and a controversial split of interventional radiology training from diagnostic radiology, the fallout from which we have yet to realize.

Other requirements mandated both before and during this perfect storm of change include the mandatory tracking of duty hours, case logs, procedures logs, trainee self-assessments, conference attendance, nuclear medicine training requirements, mammography training requirements, and 360 degree evaluations; required training elements such as learning portfolios, scholarly activity, quality projects, annual standardized testing, a 2-year repeating conference curriculum, 12 months of training 
prior to independent call, radiologic-pathologic training, and instruction in generating written reports; and competence in new required domains of education including the six ACGME core competencies, the numerous content areas found in the milestones, and other miscellaneous areas such as medical informatics, health services research, physician well-being, and cultural competency [2,6-9]. The summative impact of these changes on trainees and program directors has been staggering and yet little discussed in the radiology literature.

More is not necessarily better when it comes to GME regulation. Many program directors and coordinators spend so much of their time making measurements and enforcing accreditation policy that they are unable to spend meaningful time doing what attracted them to education in the first place, namely teaching and mentoring [10]. The mountain of new policy initiatives designed to further enhance trainee education ironically seems so onerous for some programs that it interferes with trainee education itself [11]. The sheer volume of these changes has likely contributed to feelings of burnout in even the most devoted of radiology educators $[3,11]$.

Many program directors feel as if they are treading water to keep pace with current training guidelines and GME metrics. There are so many new accessory domains of information being added to the radiology training curriculum that accrediting organizations should no longer expect individual programs to have the time, resources, or expertise to create them [12]. Even curricula in areas that some might consider basic to graduate medical education today, such as quality, professionalism, and evidence-based practice, can be difficult to provide for many training programs with limited time or expertise. Unfortunately, extrapolation of the policy curve over the last ten years tells us that there is more change to come.

Many experienced program directors who have witnessed the full impact of today's GME overregulation tell us they have one simple plea for accrediting organizations: "Don't just measure what 
you can measure, measure what matters." In fact, if the ACGME truly has the interests of trainees in mind, then they should pause to assess the summative impact of their current policies on training programs. Shouldn't ACGME policies be shown to actually improve educational outcomes before they are unveiled $[13,14]$ ? Shouldn't we expect that independent pilot studies are performed prior to the wholesale implementation of new requirements in a way that respects the ACGME's own core value of practice-based learning and improvement?

\section{A CALL TO ACTION: THE NEED FOR UNIVERSAL CURRICULA}

While we may not be able to change the current accreditation culture, we can strive to make implementation of GME policy easier for trainees and educators. Occasionally, some programs succeed at creating truly novel curricula for new learning domains, often leading to publication in the radiology literature as a means to share best practices [15-28]. However, most program directors, particularly those with limited resources, have difficulty knowing where to even start when it comes to building or adopting comprehensive new learning modules in narrow specialty areas.

In discussions with radiology educators, often at annual meetings involving members of the Association of Program Directors in Radiology (APDR), one idea consistently recurs: how can we encourage experts within our national subspecialty societies to create universal educational curricula within their areas of expertise [11]? By establishing ad hoc committees to create core content for trainee education, societies such as the Society of Imaging Informatics in Medicine (SIIM), the American Association of Physics in Medicine (AAPM), and the American College of Radiology (ACR) could add tremendous value to radiology education and the future of our specialty. If performed on a large enough scale, this kind of collaboration could free program directors from the heavy yoke of accreditation compliance, allowing them time to teach, innovate, and establish more meaningful relationships with their residents and fellows. 
Such committees could flesh out the core content areas within their fields of expertise, establishing single nationwide repositories of information that are so desperately needed by residents and program directors. Ideally, committees would decide on essential topics for inclusion in their core curricula, create written educational content covering the various topics, provide helpful practice problems or clinical vignettes, and even create examinations based on the content. These curricula would need to have one unifying feature: that with regard to both "attaining competence" and defining the content to be tested on ABR examinations, they would include the entire core domain of information such that program directors would not need to seek out additional material to supplement it.

By allowing panels of subspecialty experts to establish these kinds of comprehensive, wellvetted curricula, the content could be used in many important ways. Each curriculum could serve as the core repository of a knowledge domain from which: (1) trainees and practicing radiologists could learn and demonstrate competency; (2) ABR volunteers could write questions for the qualifying and certifying examinations; (3) ABR volunteers could write questions for maintenance of certification activities; and (4) academic and private radiology groups could create courses, lifelong learning modules, and continuing education examinations for their radiologists and trainees.

\section{DOMAINS OF NEED}

Several radiology organizations have already begun blazing the trail for universal curricula. One example is the AAPM partnership with the Radiological Society of North America (RSNA) to create the AAPM/RSNA Online Physics Modules. These modules highlight important concepts found in the AAPM physics curriculum. Originally developed in 2010 and later revised, this content currently consists of 45 individual physics learning modules spread over 10 basic categories. Although immensely helpful, these modules are only meant to serve as an educational supplement and study aid, however, and not as a 
comprehensive physics curriculum. Ideally, the AAPM would flesh out a more comprehensive curriculum from which trainees could learn the fundamental principles of imaging physics and the ABR could base their physics questions for the core examination.

Recently, a collaboration of organizations including the Society of Chairs of Academic Radiology Departments, SIIM, the ACR, and the RSNA, has started a new online initiative aimed at providing important educational content in domains that are traditionally difficult for individual programs to provide for their trainees. Their initial focus will be on improving trainee proficiency in the vital areas of informatics, big data, and health services research. A week-long online course covering the basics of informatics has already been produced, covering essential topics such as computers and networking, PACS and archiving, information security, and the business of informatics.

In what may represent the best example of a universal curriculum for trainees, radiology educators from five residency programs across the United States collaborated with leaders at the Radiology Leadership Institute (RLI) to develop an innovative pilot curriculum in healthcare economics. This curriculum included online didactic elements provided by the RLI, including web-based presentations, readings, and testing materials, and other more applied elements such as interactive meetings with local faculty and a capstone project requiring research and group collaboration. Following the success of the initial pilot run, radiology residency programs from nineteen institutions nationwide have enrolled in this year's first full length healthcare economics curriculum. This proof-of-concept exercise has enabled residency programs of various sizes and resources to successfully utilize an engaging comprehensive curriculum by way of a massive open online course model [15-16].

These early attempts at establishing national uniform training curricula show great promise. Yet substantially more needs done to meaningfully help program directors cope with the many compliance challenges facing GME. The information currently available to trainees needs expanded in both breadth 
and depth to serve as basic comprehensive curricula in their respective domains. Ideally, trainees would be able to use this vetted information as the core foundation of their learning on these subjects, and program directors would not need to seek out or create additional content to supplement it.

Based on the current accreditation landscape, we feel that radiology GME would substantially benefit from establishing nationwide curricular standards in at least twenty radiology-related content domains. The content domains and their associated radiology subspecialty societies are listed in Table 1.

\section{GME AND SUSTAINABLE CHANGE}

In today's hypermandated GME climate, the trajectory of change has increased exponentially, such that many program directors have little additional bandwidth to comply with new accreditation measures. Neither trainees nor educators in radiology know what sources to trust with well-vetted content in many of the new domains such as physician well-being, machine learning, and clinical practice management. The old convention that program directors will just find a way to make it happen has all but reached its practical limit. Currently, many educators feel that they are losing a "zero sum game" of accreditation policy that defines their struggle to both keep up with brisk GME changes and effectively prepare young radiologists for safe independent practice.

Accrediting organizations are vital members of the GME community whose actions greatly impact the abilities of trainees to learn and program directors to effectively administer their training programs. Their insulation from feedback and accountability over the past decade has led to the unsustainable level of regulation that handcuffs today's GME. As responsible stewards of their policy, they should be held to high standards for every new requirement they propose [13].

Before issuing any new policies, they should stop to reassess their current mandates, allowing independent organizations to verify that they actually improve patient or educational outcomes. They should also periodically document that the sum effect of their policy does not impair the well-being or 
relationships of trainees, program directors, or program support staff [13]. Currently, there is no reliable mechanism of feedback or system of accountability regarding the potentially damaging effects of regulation.

Until then, compliance success may require assistance from the greater radiology community. By defining and creating fundamental curricula of radiology content domains, national experts within our subspecialty societies have the opportunity to measurably improve the value that future radiologists can offer patients and other care providers. Coordinated projects to establish universal curricula would offer many opportunities for leadership, creativity, and inter-societal collaboration. Most importantly, program directors would be freed from the heavy burden of policy enforcement so that they may focus on the more meaningful educational pursuits of mentorship, innovation, and connection with their trainees.

\section{REFERENCES:}

1. Holmboe ES, Batalden P. Achieving the desired transformation: thoughts on next steps for outcomes-based medical education. Acad Med 2015;90:1215-23.

2. Amis SE. New program requirements for diagnostic radiology: update and discussion of the more complex requirements. AJR Am J Roentgenol 2008;190:2-3.

3. Mullins ME, Gunderman RB. Change overload and the program director. Acad Radiol 2015;22:539-40.

4. Alderson PO, Becker GJ. The new requirements and testing for American Board or Radiology certification in diagnostic radiology. Radiology 2008;248:707-09.

5. Pfeifer CM. Changes to radiology: simpler is better. Acad Radiol 2015;22:1326-7. 
6. Nasca TJ, Philibert I, Brigham T, Flynn TC. The next GME accreditation system - rationale and benefits. N Engl J Med 2012;366:1051-6.

7. Vydareny KH, Amis ER, Becker GJ, et al. Diagnostic radiology milestones. J Grad Med Educ 2013;5:74-8.

8. Nicholson BT, Paladin AM, Oldham SA, et al. The Next Accreditation System in radiology: a report from the APDR residency structure committee. J Am Coll Radiol 2014; 11:407-12.

9. Larson DB. Major changes in radiology residency program requirements are coming. AJR Am J Roentgenol 2007;188:3-4.

10. Ruchman RB, Kwak AJ, Jaeger J, Sayegh A. Job satisfaction of program directors in radiology: a survey of current program directors. AJR Am J Roentgenol 2013;200:238-47.

11. Webber GR, Baumgarten DA, Chen Z, Wang Z, Mullins ME. A survey of diagnostic radiology residency program directors and the increasing demands of program leadership. J Am Coll Radiol 2013;10:523-6.

12. Heard JK, Allen RM, Clardy J. Assessing the needs of residency program directors to meet the ACGME general competencies. Acad Med 2002;77:750.

13. Gunderman RB, Mullins ME. Bureaucracy and the future of residency education. Acad Radiol 2012;19:249-51.

14. Yuan CM, Abbott KC, Oliver JD. The next GME accreditation system. N Engl J Med 2012;366:2324-5.

15. Prober AS, Mehan WA, Bedi HS. Teaching the healthcare economics milestones to radiology residents: our pilot curriculum experience. Acad Radiol 2016;23:885-8.

16. Prober AS, Ledermann E, Norbash A, Mehan WA, Bedi HS. Fulfilling the health care economics milestones: adopting an online curriculum for radiology residency programs. J Am Coll Radiol 2015;12:314-7. 
17. Leddy R, Lewis $\mathrm{M}$, Ackerman S, et al. Practical implications for an effective radiology residency quality improvement program for milestone assessment. Acad Radiol 2017;24:95-104.

18. Amrhein TJ, Tabesh A, Collins HR, Gordon LL, Helpern JA, Jensen JH. Instituting a radiology residency scholarly activity program. Educ Health (Abingdon) 2015;28:68-73.

19. Cronin P, Rawson JV, Heilbrun ME, et al. How to critically appraise the literature. Acad Radiol 2014;21:1117-28.

20. Chertoff J, Pisano E, Gert B. Core curriculum: research ethics for radiology residents. Acad Radiol 2009;16:108-16.

21. Lown BA, Sasson JP, Hinrichs P. Patients as partners in radiology education: an innovative approach to teaching and assessing patient-centered communication. Acad Radiol 2008;15:42532.

22. Brandon CJ, Mullan PB. Teaching medical management and operations engineering for systemsbased practice to radiology residents. Acad Radiol 2013;20:345-50.

23. Otero HJ, Weissman BN, Rybicki FJ. System-based practice: proposal for a comprehensive curriculum. Acad Rdiol 2008;15:119-26.

24. Deitte L. Learning portfolios in radiology residency education: how do I get started? J Am Coll Radiol 2008;5:664-9.

25. Siddiqui KM, Weiss DL, Dunne AP, Branstetter BF. Integrating imaging informatics into the radiology residency curriculum: rationale and example curriculum. J Am Coll Radiol 2006;3:52-7.

26. Branstetter BF, Bartholmai BJ, Channin DS. Reviews in radiology informatics: establishing a core informatics curriculum. J Digit Imaging 2004;17:244-8.

27. Deitte L. The new residency curriculum: professionalism, patient safety, and more. J Am Coll Radiol 2013;10:613-7. 
28. Shankar PR, Woodard J, Heller MT, Agarwal V, Orons PD. Implementation and outcomes of a resident-led physics curriculum with integration of the RSNA/AAPM physics modules. Acad Radiol 2013;20:1306-10. 